\title{
Developing Indigenous Australian cultural competence: a model for implementing Indigenous content into curricula
}

\author{
Helen Flavell ${ }^{1}$, Rosalie Thackrah ${ }^{1}$, Julie Hoffman ${ }^{1}$ \\ H.Flavell@curtin.edu.au; R.Thackrah@email.curtin.edu.au; J.Hoffman@curtin.edu.au \\ ${ }^{1}$ Faculty of Health Sciences, Curtin University
}

\begin{abstract}
This case study describes the implementation of a stand-alone unit on Indigenous Australian culture and health within a nursing and midwifery program, and presents quantitative and qualitative data from the university's anonymous online student teaching and learning questionnaire. In doing so, this study aims to determine whether a single, compulsory unit has the capacity to develop graduate Indigenous Australian cultural competence.
\end{abstract}

Qualitative data from the nine teaching periods over the five years the unit was taught is analysed to determine student satisfaction and motivation. A total of 1742 students enrolled in the unit over five years and 748 completed the online questionnaire (a response rate of 43\%). Qualitative data from the same teaching and learning questionnaire is drawn on to highlight the impact of the unit on student attitudes towards Aboriginal and Torres Strait Islander peoples, as well as the pedagogical approaches adopted to teach compulsory Aboriginal studies to predominately non-Aboriginal students.

Data suggests that overall students were satisfied and engaged with the unit. For many the experience was transformative, not having had prior experience with Indigenous Australians or Aboriginal studies' content. A discrete unit on Indigenous culture and health has the capacity to assist students to begin their journey to cultural competence. However, to be successful and sustainable, such a unit must be aligned with the three key areas identified in a Reconciliation Action Plan: relationships, respect and opportunities. Furthermore, key pedagogical approaches are required to ensure students are motivated to engage with the content.

Keywords: Indigenous Australian cultural competency, cross-cultural graduate capability, Indigenising curricula, cross-cultural pedagogy, intercultural education

It is with respect that we acknowledge the Nyungar people and their Elders, who are the custodians and guardians of this land on which we live. We thank the Elders for their continued guidance and support of the work that we do in the interests of improving outcomes for all Aboriginal and Torres Strait Islanders.

\section{Introduction}

Across all typical markers to gauge a population's well-being-education, employment, socio-economic standing, representation in the criminal justice and child protection systems, and health-the statistics for Aboriginal and Torres Strait Islanders are disproportionately poor (Turale \& Miller, 2006). The literature concerned with improving outcomes for Aboriginal 
and Torres Strait Islanders ${ }^{1}$ consistently emphasises the need for the provision of culturally appropriate inclusive practices characterised by partnerships between Indigenous and nonIndigenous Australians across all sectors. Therefore, whilst other approaches are required, one important mechanism for improving outcomes for Aboriginal and Torres Strait Islanders is to develop culturally competent graduates able to demonstrate an understanding of Indigenous Australian culture and history, as well as the ability to communicate effectively with community to deliver culturally appropriate and effective services (Behrendt, Larkin, Griew \& Kelly, 2012; Charles Sturt University, 2013; Grote, 2008; Leaders in Indigenous Medical Education (LIME); Universities Australia, 2011). Recent reports, such as that of Universities Australia (2011), indicate that there is increasing emphasis on graduate Indigenous cultural competency in Australian higher education. In fact the Universities Australia report recommends that Indigenous cultural competency be included as a formal graduate attribute and this recommendation stems from earlier work by the Indigenous Higher Education Advisory Council (2006) as well as individual Aboriginal and Torres Strait Islander academics (Collard, Walker \& Dudgeon, 1998; Nakata, 2007a). The Review of Higher Education Access and Outcomes for Aboriginal and Torres Strait Islander People Final Report (Behrendt et al., 2012) similarly recommends aligning graduate capabilities and Indigenous knowledge and perspectives (Recommendation 14). According to Yorke (2006) graduate attributes are: the skills, understandings and personal attributes that make an individual more likely to secure employment and be successful in their chosen occupations to the benefit of themselves, the workforce, the community and the economy (p.8). Currently, most Australian universities include an attribute related to ethical and inclusive engagement with communities, cultures and nations (Oliver, 2011, p. 3). According to Universities Australia (2011) only nine Australian universities include reference to Indigenous people and cultures within their graduate attributes or qualities, although most require their graduates to develop skills in cross-cultural awareness and communication.

Attributes related to cultural competency, however, tend to be embedded into the curriculum poorly and rarely measured and assured (Oliver, 2011). Generally speaking, academics are most comfortable with embedding discipline specific attributes (de la Harpe et al., 2009). What makes embedding cultural competency as a generic graduate attribute challenging is that cultural competency and cross-cultural education are complex and specialised areas of teaching and learning, and few academics have the confidence, skills and ability to teach and assess these capabilities effectively (de la Harpe et al., 2009; Nash, Mieklejohn \& Sacre, 2006). Added to this, in the context of postcolonial Australia, a nation founded through colonisation, many academics have a lack of knowledge and understanding of Aboriginal and Torres Strait Islander cultures and history (Universities Australia, 2011), they frequently cannot make the connection between their unit and Indigenous perspectives and are anxious about undertaking inappropriate activities (Williamson \& Dalal, 2007). Furthermore, in some instances, researchers in the field report 'territorial' responses from non-Aboriginal academics who identify an already overcrowded curriculum as a barrier to including Indigenous Australian history, culture and knowledge (Gunstone, 2009; Nakata, Nakata \& Chin, 2008). Another related factor to preventing the incorporation of Indigenous content in a way that supports cultural competence development is that Indigenous perspectives and experience often gets lost among broader considerations leading to 'one off' presentations by an Indigenous guest speaker (Wimshurst, Marchetti \& Allard, 2004). Whilst this can be a starting point and a way to build relationships, it is not enough to continue with guest lectures; a more scaffolded approach is required (Universities Australia, 2011).

\footnotetext{
${ }^{1}$ In respect of the diversity of Indigenous Australians, 'Aboriginal and Torres Strait Islander' has been used in this paper to refer to the original custodians and guardians of the land which makes up what is now known as Australia. However, at times, 'Indigenous Australians' is also used as this is a phrase often found in the literature exploring Aboriginal and Torres Strait Islander cultural competency. The authors acknowledge that many of these terms are contentious and problematic, and that some Aboriginal people prefer to be identified by their language group. The authors respectfully apologise for any offence that may be caused.
} 
Despite these challenges, a number of universities and disciplines have worked to embed Indigenous Australian perspectives into their curriculum. For example, it is a requirement that pre-service teachers complete compulsory content on Indigenous Australia to achieve the Graduate Teacher Standards (Australian Institute for Teaching and School Leadership, 2012). In engineering at the University of South Australia work has been done to include Indigenous knowledge into the curriculum to develop the cultural competence of graduates (Duff, Brodie, Furber-Gillick, Quinn \& Smith, 2011), as is also the case in criminal justice studies at Griffith University (Wimshurst et al., 2004) and Queensland University of Technology (Grote, 2008). Heath education curricula has made some significant progress towards embedding relevant content (Grote, 2008; Nash et al., 2006; Ranzijn et al., 2008; Raymond, 2008), the development of a curriculum framework for medical education (Phillips, 2004) as well as efforts to showcase best practice case studies (LIME, 2012). Furthermore, Health Workforce Australia has announced a new national project to develop an Indigenous curriculum framework for incorporation into undergraduate tertiary level health professional training (Health Workforce Australia, 2013). More broadly, however, several universities are leading the way by committing to embedding Indigenous knowledge into all undergraduate programs of study, including Charles Sturt University (Grote, 2008; Universities Australia, 2011), the University of South Australia (Duff et al., 2011), the University of Western Sydney (Anning, 2010), and Griffith University (Universities Australia, 2011). Although not a complete list, the range and level of activity in higher education to address Indigenous cultural competence confirms the need for non-Aboriginal academic staff to build their skills and confidence to teach in this area in a culturally respectful manner.

\section{Aims}

This case study aims to contribute to the body of knowledge on teaching Indigenous Australian content to non-Indigenous Australian students by addressing the research question: can a compulsory stand-alone unit develop graduate Indigenous Australian competence? Specifically the study will:

1. Provide a conceptual framework for Indigenous Australian cultural competence.

2. Describe the context, pedagogical approaches and implementation of a compulsory unit titled Indigenous Australian Health and Culture (IAHC) within a nursing and midwifery program.

3. Provide evidence of the outcomes of IAHC in relation to graduate Indigenous Australian cultural competence.

4. Explore some of the complexities of teaching at the 'cultural interface' (Nakata, 2007a). Furthermore, the paper provides some insight and practical strategies for managing the tensions inherent in this space.

\section{Conceptual Framework: Indigenous Australian Cultural Competence}

Cultural competence is a complex and contested concept (Thackrah \& Thompson, 2013; Universities Australia, 2011) which builds on other related terms such as cultural awareness, cultural security, cultural respect, cultural safety (Gower, Nakata \& Mackean, 2007), culturally responsive (MacMillan, 2013) and cultural humility (Tervalon \& Murray-Garcia, 1998). Most of these concepts come from health. In Australia, in relation to Aboriginal and Torres Strait Islander peoples, there is debate regarding what constitutes cultural competence and whether it can ever be achieved by non-Aboriginal people (Nakata, 2007a). Criticism has also been made of 'cultural competency' which has an implied finality that does not mirror the life-long self-reflection required to be culturally responsive (MacMillan, 2013). According to Coffin (2007), cultural awareness is the first step, and typically this form of cross-cultural education provides information about basic cultural protocols and appropriate,

Flavell, H., Thackrah, R. \& Hoffman, R. (2013). Developing Indigenous cultural competence: A model for implementing Indigenous content into curricula. 
respectful ways of being in Aboriginal communities. Cultural safety, however, is more sophisticated and requires individuals to combine cultural awareness with an ability to adjust their treatment of an Aboriginal person (evident through actions and gestures). Significantly, cultural safety is a term that developed in the 1980s in New Zealand in response to the colonial history of Aotearoa (New Zealand) and specifically out of Maori consumer dissatisfaction with nursing care (Eckermann et al., 2010, p. 184). Following on from cultural safety, cultural security includes brokerage and protocols where (a) all parties involved are equally important and informed, and (b) where an Aboriginal context is formally recognised through the involvement of community and Elders (Coffin, 2007, pp. 22-23). The terms cultural awareness, safety, security and competence are often used loosely and interchangeably (Coffin, 2007; Grant, Parry \& Geurin, 2013), risking not only the complexity of cultural competence being overlooked but also a tendency for students and graduates to assume that they have attained the level of competence required or, in the case of academics, sufficiently addressed the 'issue' in their course or curriculum. It is important to consider that one-off experiences have limited capacity to achieve cultural competence (Lawrence \& Bunche, 1996). Similarly, recent research has demonstrated that mere cultural awareness training is not sufficient to develop cultural competence as it tends to essentialise Indigenous Australians, ignoring the diversity within populations and often evokes a static notion of culture rather than culture as dynamic and changing (Carpenter-Song, Nordquest Schwallie \& Longhofer, 2007; Downing \& Kowal, 2011).

Gower et al. (2007) define Indigenous Australian cultural competence as building on the attributes of awareness, knowledge, understanding, sensitivity, interaction, proficiency and skill to interact with others. It can be viewed as a non-linear and dynamic process which integrates and interlinks individuals with the organisation and its systems (p. 36). Their definition is useful as it recognises the developmental continuum of cultural competence (Campinha-Bacote, 2002), the need for critical self-reflexivity (Banks, 1994), an interrogation of the power relations inherent in intercultural exchange, as well as the skills, knowledge and understanding to adapt service delivery to meet Indigenous Australians' needs (Coffin, 2007). In the (post) colonial state, graduate Indigenous Australian cultural competence is of particular relevance due to the legacy of historical and enduring racism on Aboriginal and Torres Strait Islander peoples.

\section{Pedagogical Approaches}

In the context of Australian history, education and, indeed, the formation of the nation on the White Australia Policy, developing graduate capabilities of cultural competence in relation to Aboriginal and Torres Strait Islander presents particular challenges (Gunstone, 2009). For example, according to the Indigenous Higher Education Advisory Council (2006) knowledge of Indigenous history and culture is very low in white Australia-possibly even at a trivial level (p.8). Similarly, Universities Australia (2011) argue that many academics and students confirm that they have had little or no exposure to this topic at school or university levels ( $p$. $60)$.

As a consequence of this lack of knowledge and experience, the majority of non-Aboriginal Australians hold stereotypical notions (White, Frawley \& Dang Thi, 2013), and many have developed their opinions on Indigenous Australians through the media and popular mythology (for example, extensive, 'special' social security payments for Aboriginal Australians) (ATSIC, 1999; Duffy, Harju, Huittinen \& Trayner, 1999; Mickler, 1998; Morgan \& Golding, 2010; White et al., 2013). For non-Aboriginal students who comprise the dominant group there is a continuing notion that minority groups such as Aboriginal and Torres Strait Islanders are offered advantages they as the 'majority' cannot access (Wimshurst et al., 2004). Added to this, no individual wants the stigma of being identified as a racist (O'Dowd, 2010). Yet, as has been noted in research into non-Aboriginal student attitudes, racist discourses about Indigenous Australians tend to be normalised in everyday life (Mitchell,

Flavell, H., Thackrah, R. \& Hoffman, R. (2013). Developing Indigenous cultural competence: A model for implementing 
Every \& Ranzijn, 2011). Teaching in this space, therefore, requires skilful pedagogical approaches that draw students to express their ideas whilst shifting their viewpoint. With limited understanding and knowledge of Indigenous cultures, history and world views, combined with a lack of knowledge about the history of colonisation in Australia and popular stereotypes, many non-Indigenous students do not immediately appreciate the relevance of a course or unit on Indigenous Australian studies. The published literature in the field clearly identifies student resistance to compulsory Indigenous content as a barrier to developing Indigenous cultural competence (Charles Sturt University, 2013; O'Dowd, 2010; Wimshurst et al., 2004). Interestingly, negative responses from students from the majority group tend to fall into common patterns of objection which have been recorded in other (post) colonial contexts (Crey \& Perrault, 2007). These include those mentioned above such as the perceived special treatment of minorities, a lack of understanding of the relevance of the content to them and their profession, arguments that all this 'happened in the past' and to other groups (for example, the forced removal of poor English children who were sent to Australia), and why don't Aboriginal and Torres Strait Islanders 'just move on.' Although not representative of all students' reactions to compulsory content on Aboriginal and Torres Strait Islanders, resistance is evident from non-Aboriginal students. Similarly, it is important to recognise that not all students will respond the same way depending on their own experiences, understanding and knowledge of their racial identity when they enter a unit such as IAHC. In fact, for some students there may never be a shift in attitudes during the course. Anecdotal evidence from academics teaching the unit explored here (IAHC) suggests that any transformation may occur years after completion; an ex-student contacted a lecturer up to two years later to let them know they finally 'got it!' This reflects the specialised nature of teaching and curriculum development in cultural competency education and the complexities of intercultural education.

In North America, and in the field of whiteness studies, there has been considerable work in the area of racial identity formation, which has been applied to cultural competence (for example Howard, 1999; Singleton \& Linton, 2006). Many of the models of racial identity, such as those developed by Helms (1990), indicate that the realisation of oneself as a racialised being is a process - part of a continuum - rather than something which is achieved through a single event (Campinha-Bacote, 2002). Helm's (1990) theory of racial identify formation implies that singular exposure to alternative views/positionings of self/identity are not enough to develop cultural competence particularly when one is part of the dominant group. Consistent with the conceptualisations of cultural competence provided above, oneoff experiences are not sufficient to develop cultural competence as ideally, Indigenous content and cross-cultural/cultural competence pedagogy should be scaffolded vertically through the curriculum (as well as horizontally) (Universities Australia, 2011). This gives students the opportunity to build on their knowledge and experiences in this area as they progress through their degree. Indeed even the most experienced person working within Aboriginal contexts needs to be aware that cultural competencies have to be regularly evaluated and adjusted to meet changing cultural environments (MacMillan, 2013).

Academics involved in cross-cultural education need to have reflected on their own racial and ethnic identity and understand the journey undertaken in recognising one's own particular racial and ethnic biases and cultural lenses. They also require a sound knowledge of cross-cultural pedagogy as cross-cultural learning and identity development are complex processes that involve many factors such as age, gender, ethnicity, race, social-class, and sexual orientation (McAlister \& Irvine, 2000, p. 6). As already argued, teaching Indigenous Australian health and culture presents challenges given the nation's dominant colonial discourses and the prevalence of Western epistemology (Jarvis-Selinger et al., 2008) and ontology in the academy (Nakata, 2007b). The associated challenges are particularly evident when the inclusion of Indigenous Australian content is compulsory (Asmar \& Page, 2009). As suggested earlier, students move along a continuum of cultural competence to recognise their culturally specific world view, biases, ethnicity and associated privilege and for many

Flavell, H., Thackrah, R. \& Hoffman, R. (2013). Developing Indigenous cultural competence: A model for implementing Indigenous content into curricula.

Journal of Teaching and Learning for Graduate Employability, 4(1), 39-63. 
white Australian students one of the stages of this continuum is guilt (Helms, 1990; Williams, 2000). To address such stumbling blocks to learning and cross-cultural capability development, the learning experiences need to be constructed and sequenced to support and motivate student learning. They also need to provide a framework for effective interventions to promote attitudinal change. For example, notions of white privilege should not be introduced early in the curriculum as this can enhance feelings of guilt and stall the development of an integrated, positive racial identity (McAllister \& Irvine, 2000).

\section{The Design and Implementation of Indigenous Australian Health and Culture}

Indigenous Australian Health and Culture was introduced to the School of Nursing and Midwifery (SOMN) in 2006 and taught to first year students. Significantly, the unit received the Australian Office for Learning and Teaching Neville Bonner Award in 2010 for outstanding contribution to Indigenous Education and reflects current good practice as identified in the literature (Universities Australia, 2011). The success of IAHC and its approach, including the development of relationships between the University's Centre for Aboriginal Studies (CAS) and SOMN staff, has enabled and supported the introduction of a new compulsory unit which is taught across the Faculty of Health Sciences' 21 disciplines to approximately 2,300 students annually (Kickett, Hoffman \& Flavell, 2013 ). The introduction of this new wide-scale compulsory unit in 2011 was a major achievement for the University and aligns with the University's commitment to a Reconciliation Action Plan (RAP). Such plans are structured around three key areas: relationships, respect and opportunities (Reconciliation Australia, 2005-2012), and IAHC was designed and implemented with these three areas in mind.

For example, although the majority of enrolled students in IAHC were non-Indigenous (both Australian and International), IAHC, which was informed by research and best practice, was part of a multi-pronged approach to increase Indigenous Australian participation in nursing and midwifery. Furthermore, it aimed to improve outcomes for Aboriginal and Torres Strait Islanders and address the discrepancy between outcomes for Indigenous Australians and the broader non-Indigenous Australian population (Office of Aboriginal and Torres Strait Islander Health, 2002). Indigenous Australian Health and Culture worked in conjunction with several other initiatives including:

\section{Relationships}

- links with Aboriginal community and health organisations to provide recruitment pathways for students;

- a student mentoring program;

Respect

- cross-cultural training for non-Indigenous staff (teaching and administrative);

\section{Opportunities}

- the establishment of an Indigenous Australian academic staff position within SONM;

- scholarships for Aboriginal and Torres Strait Islander students;

- reserved places for Aboriginal and Torres Strait Islander students within SONM's programs.

This multi-faceted approach reflecting the RAP framework was (and is) needed due to the number and complexity of barriers limiting Indigenous Australian participation in health professions and their access to culturally secure services. According to Universities Australia (2011) merely embedding content is not enough to achieve cultural competence, there needs to be a systematic approach in higher education to achieve graduate Indigenous Australian cultural competence. In the same way, many working in the field have 
identified the need for key principles to underpin any 'Indigenisation of the curriculum' (Nash et al., 2006; Ranzijn, McConnochie, Nolan \& Day, 2007).

One of those key principles_-identified in a RAP_-is partnerships with community. Modelling the importance of partnerships in improving outcomes for Indigenous Australians (Duff et al., 2011; Gunstone, 2009; White et al., 2013), IAHC developed from relationships built over a long period of time between SONM, CAS, Aboriginal Elders, community groups and Aboriginal health workers. In fact, without the strong central partnership between CAS and SONM this unit would have been impossible and certainly its expansion to the new Facultywide compulsory unit unlikely. Initial collaboration toward the unit between CAS and SONM began in 1997, however, the introduction of a Memorandum of Understanding (MOU) in 2002 helped strengthen the relationship. On the basis of this MOU-which privileges Aboriginal Terms of Reference-staff from CAS led the implementation of IAHC and the development of the curriculum. The MOU was an important symbol of respect essential to building trusting relationships. The Centre for Aboriginal Studies and SONM continue to work collaboratively to teach the new interprofessional first-year unit that has replaced IAHC; which is co-coordinated by a Nyungar and wadjela (non-Aboriginal) academic and continues the tradition of respectful collaboration. Table 1 below provides an overview of the weekly topics; guest lectures were provided by local Aboriginal health workers and staff from CAS.

\section{Table 1: IAHC Weekly Topics}

\section{Week Tutorial topic/s}

1 Kaya...welcome...

Welcome to Country - by Nuyngar Elder

Cultural spaces and Indigenous identity

Terms of Reference and terminology

\section{$2 \quad$ Why bother?}

Working in Indigenous Australian contexts-Relevance to Nursing?

Historical overview - Past policies and practices

\section{Contemporary Indigenous Australian contexts}

Identity and diversity.

Guest Indigenous speaker

$4 \quad$ Indigenous terms of reference

Indigenous Australian terms of reference in practice

Guest Indigenous speaker

5 Issues in cross-cultural communication

Working in Indigenous Australian Contexts

Guest Indigenous speaker

6 Indigenous health

Aboriginal health: Getting better? Getting involved?

Guest Indigenous speaker 


\section{$7 \quad$ Indigenous mental health}

Guest Indigenous speaker

\section{$8 \quad$ Contemporary issues in Indigenous health}

Indigenous health policy and practice today; brief history of Indigenous health organisations; two systems of health care service, Indigenous \& Mainstream; urban, remote \& rural area issues; Working towards a partnership in the delivery of care to Indigenous Australians; Indigenous health care programs; role of the Indigenous Health worker

Guest Indigenous speaker

\section{$9 \quad$ Contemporary view of Indigenous health}

Comparison of Indigenous and mainstream health statistics; morbidity and mortality statistics in full; children's health eg infant mortality, immunisation, infection; men's health eg violence, injury, alcohol; women's health e.g. fertility, diseases.

Guest Indigenous speaker

\section{Practical strategies for effective working relationships}

'Where to from here?'

Taking into account the developmental continuum of cultural competency and the stages of the journey including a period of guilt for non-Aboriginal students (Helms, 1990; Williams, 2000), IAHC began with broad exposure to Aboriginal and Torres Strait Islander health issues and moved towards challenging the views and assumptions of students. Understanding the emotional process of non-Aboriginal Australian students when exposed to Aboriginal studies is important in assisting those teaching to support students on their journey. One of the key methods adopted in a carefully sequenced approach to the content is one of 'no blame' where students are encouraged to discuss a range of viewpoints in an informal and non-judgemental context. This helps students to explore their views with an understanding that this knowledge is new to them; this approach has been identified by others working in the field as an important element in creating a safe learning environment in which concerns can be raised and addressed whilst seeking to shift understanding (O'Dowd, 2010; Williamson \& Dalal, 2007). Students were supported and at the same time challenged to reassess their ideas regarding Indigenous Australians-and how they have been constructed-through round table yarning sessions that model Indigenous cultural pedagogies and protocols, mutual respect and draw the audience into the speaker's circle (Bessarab \& Ng'andu, 2010; Yunkaporta \& Kirby, 2011). Incorporating Indigenous Australian ways of teaching and learning in Aboriginal studies is significant as it reconfirms Aboriginal and Torres Strait Islander ways of being and knowing, as well as emphasising that Western pedagogy, although privileged in Australian higher education, is one of many models of learning.

Similarly, students were challenged to explore where their knowledge of Indigenous Australia comes from. This was facilitated through a variety of guest Indigenous Australian lecturers, tutorial discussion and reflection, selected readings and assessment activities, and as many opportunities to engage with Aboriginal people as possible. Yarning with members of the Stolen Generation and hearing of experiences of racism and discrimination from

Flavell, H., Thackrah, R. \& Hoffman, R. (2013). Developing Indigenous cultural competence: A model for implementing 
Aboriginal professionals and fellow university students moves students to reflect on their assumptions and personalises statistics which, it has been argued, tend to be glibly repeated to the point where most non-Indigenous Australians no longer register their personal or community significance (Morgan \& Golding, 2010, p.12) Such personalised encounters bring home the lived experience of Aboriginal and Torres Strait Islanders. This is the essence of the unit which incorporated real people with real stories to tell, and demonstrates why there was such an emphasis on employing Aboriginal tutors and lecturers.

The respectful relationship between CAS and SONM, which informed the unit, also enabled partnerships with Indigenous organisations outside the university such as the Marr Mooditj Foundation, which is a registered training organisation delivering courses in primary health care and enrolled nursing for Aboriginal students. Such networks have meant that a wide range of experts on Indigenous Australian health and culture have been willing to provide lectures. Many of the lecturers are highly regarded experts who are in great demand, such as Dr Joan Winch who is a respected Nyungar Elder, founder of Marr Mooditj, Premier's Indigenous Leaders Scholar and the recipient of national and international awards. The guest speakers are, therefore, not just experts in the field of Indigenous health they are cultural knowledge holders who command respect in both Indigenous and non-Indigenous communities.

Whenever possible (to meet with tuition patterns in CAS) IAHC students were given the opportunity to meet and interview Aboriginal students. Such experiences are invaluable work-integrated-learning opportunities and a privilege for non-Indigenous students who more often than not move in a world completely removed from the realities of life for Indigenous Australians. The learning experiences provided by IAHC, therefore, go some way to challenging 'cultural encapsulation' (Banks, 1994) or isolation, a barrier to cross-cultural competency. Most importantly, however, the design and implementation of the unit was underpinned by relationships, respect and opportunities as outlined in the RAP framework.

\section{Methods}

Student feedback on their learning experiences of IAHC was gathered using eVALUate, which is the University's online unit evaluation survey. Student feedback was collected from nine study periods from the first semester the unit was introduced in semester two, 2006, to semester two, 2010 (there are two semesters each year which are the two major annual teaching periods). As mentioned earlier, in 2011 IAHC was replaced with a core interprofessional unit (Kickett, Hoffman \& Flavell, 2013 ). Ethics approval to use anonymous student feedback data was granted through the University's Ethics Committee.

The online unit survey has eleven quantitative items and two qualitative items. The survey asks students to report their perceptions of what helps them to achieve the unit learning outcomes (items 1 to 7), their engagement and motivation (items 8 to 10) and overall satisfaction (item 11). For each quantitative item, students rate their level of agreement (strongly agree, agree, disagree strongly disagree) or select 'unable to judge' (Tucker \& Pegden, 2010). The two qualitative items include 'Comment on the most helpful aspects of the unit' and 'how the unit might be improved'.

Over the nine semesters 1,742 students were enrolled in the unit and a total of 748 of those students responded to the online teaching questionnaire (with an overall response rate of $43 \%)$.

Flavell, H., Thackrah, R. \& Hoffman, R. (2013). Developing Indigenous cultural competence: A model for implementing 


\section{Results}

\section{Quantitative Data}

Quantitative student feedback through the University's online student survey for teaching and learning suggests that overall learning experiences were well received and valued (Table 1). This is particularly so from the second year that IAHC was offered (2007) onwards, where percentage agreement was at $80 \%$ and above (with the exception of semester one, 2009 for Overall Satisfaction). Quantitative feedback from students indicates that the majority were satisfied with the teaching and the unit, which was above university averages for Items 7 (Teaching Quality) and 8 (Motivation) for seven of the nine semesters it was taught. For Item 11 (Overall Satisfaction), IAHC achieved above university percentage agreement for seven of the nine semesters it was taught.

\section{Table 2: eVALUate Quantitative Data for Items 7, 8 and 11 (percentage agreement)}

\begin{tabular}{|c|c|c|c|c|c|c|c|c|}
\hline \multirow{2}{*}{$\begin{array}{c}\text { Year } \\
\text { /Semester }\end{array}$} & \multirow{2}{*}{$\begin{array}{c}\text { Student } \\
\text { Enrolment }\end{array}$} & \multirow{2}{*}{$\begin{array}{c}\text { Response } \\
\text { Rate }\end{array}$} & \multicolumn{2}{|c|}{$\begin{array}{c}\text { Item } 7 \\
\text { Teaching Quality }\end{array}$} & \multicolumn{2}{|c|}{$\begin{array}{c}\text { Item } 8 \\
\text { Motivation }\end{array}$} & \multicolumn{2}{|c|}{$\begin{array}{c}\text { Item } 11 \\
\text { Overall } \\
\text { Satisfaction }\end{array}$} \\
\hline & & & $I A H C$ & $\begin{array}{l}\text { University } \\
\text { percentage } \\
\text { agreement }\end{array}$ & $I A H C$ & $\begin{array}{l}\text { University } \\
\text { percentage } \\
\text { agreement }\end{array}$ & $I A H C$ & $\begin{array}{l}\text { University } \\
\text { percentage } \\
\text { agreement }\end{array}$ \\
\hline $2006 / 2$ & 166 & $48 \%$ & 62 & 78 & 67 & 82 & 51 & 80 \\
\hline $2007 / 1$ & 139 & $40 \%$ & 82 & 80 & 87 & 83 & 83 & 82 \\
\hline $2007 / 2$ & 158 & $44 \%$ & 90 & 80 & 89 & 83 & 90 & 81 \\
\hline $2008 / 1$ & 139 & $39 \%$ & 93 & 81 & 85 & 84 & 87 & 82 \\
\hline $2008 / 2$ & 183 & $49 \%$ & 83 & 82 & 89 & 84 & 91 & 83 \\
\hline $2009 / 1$ & 106 & $41 \%$ & 91 & 82 & 95 & 84 & 79 & 83 \\
\hline $2009 / 2$ & 204 & $38 \%$ & 95 & 83 & 85 & 84 & 91 & 83 \\
\hline 2010/1 & 142 & $44 \%$ & 95 & 83 & 92 & 85 & 85 & 83 \\
\hline $2010 / 2$ & 505 & $43 \%$ & 78 & 84 & 73 & 85 & 67 & 84 \\
\hline
\end{tabular}

Qualitative feedback

Qualitative student comments similarly confirm that the teaching within the unit engaged and motivated students:

"The entire unit was excellent. The enthusiasm and passion of the tutor encouraged us to attend each week - I liked going to class! There were definite learning outcomes and gave incentive to go and find out more...Brilliant."

"Every part of this unit was very interesting and I was motivated to do extra work.... I especially like how there was a range of group assignments and individual assignments. XXX was a great help, excellent teaching and guidance." 
" $\mathrm{i}$ found this unit to be very appropriate and informative, the guest speakers were all fantastic, i noticed that of all the units for sem 2 this unit was consistent with people showing up to lectures right through to the last, whereas others units decreased to 6-8 students by the end of semester."

Similarly, being able to attract-through respectful partnerships-Aboriginal health professionals and experts was also well received and assisted students to appreciate the diversity of Indigenous Australians and their experience.

"Having people who are actively involved in the health care of Aboriginal Australians made the unit real and relevant."

"Guest lecturers gave relevant and diverse experiences to expand students' views."

"I feel because XXX, an Indigenous Australian, was my tutor and he was very open to informing students of the difficulties most Australian Aborigines face I was helped to understand the problems the Indigenous Australians face in their everyday lives. I am now more tolerant of why \& how some people respond to oppression. I think that in the future I would like to work in remote communities. I will be continuing my studies on Indigenous Australian Culture and Health problems."

"I gained a better understanding of the Aboriginal culture and was made aware that there are many groups of Aboriginal people throughout Australia all with their own culture. The most useful part of the course was when XXX told her story."

"I really enjoyed this unit especially the interview this really helped me to understand what the whole unit was about and I got a deeper understanding of what Indigenous Australians have been through and why things are the way they are now."

Consistent with the literature, and as the feedback from students of IAHC indicates, the reality for the majority of urban non-Indigenous Australians entering the tertiary system is that they frequently have not met an Aboriginal person nor do they have knowledge, or an understanding, of the history of colonisation in Australia and the profound effect of historical, socio-cultural and political factors on the well-being of Aboriginal and Torres Strait Islander peoples.

"It was interesting and learning about our history was good, the first time."

"Having minimal interaction with Indigenous Australian people, and having never been involved in any Indigenous Studies before (in previous university degree). I learned a lot about various factors that affect Indigenous health. I also learned about resources I can access in order to learn more on various topics, and the knowledge I have gained will help me when I am working in Indigenous contexts."

"I only wish that all students could have the opportunity to do this unit as I think that would help a lot."

Echoing non-Aboriginal students' views a comment from an Aboriginal student of IAHC indicates that it comes as no surprise that non-Aboriginal students have a lack of understanding and knowledge of Aboriginal and Torres Strait Islanders, their history and culture. 
“... being aboriginal. It gave other students an idea of ab'l issues and the way it affects us"

The sequencing of the learning experiences, including the learning environment or tone of interactions, was created to enable adequate space for reflection and the development of students' awareness of their own ethnic and racial self-identity, worldviews and belief systems. Students were encouraged to explore a range of texts from an Indigenous perspective, including films, plays, television documentaries and fiction. Importantly, the discussions that ensued in the tutorial groups from these texts and the unit readings are focussed on understanding the importance of privileging Aboriginal Terms of Reference as a health care professional when dealing with Indigenous Australian clients.

"Having an environment, and tutor that allows ++group discussion is very helpful as it evokes a lot of different questions, ideas etc which overall improves the quality of our learning. The tutorials have flexibility in content in this regard which is great."

"XXX's unbiased view point allowed our class discussions that at time got quite heated, to see two points of view and be more open minded. I will certainly see other races differently after taking this class and may better be able to empathise with them."

"It was well designed, in the way that it looked at everything to do with Indigenous health. It started off with colonisation/history and then gently led to other broader sections."

"An interesting semester. I was not quite sure what to expect on the first day of class. I think just having this subject is helpful enough in being able to understand the injustice of our fellow Indigenous Australians. Allowing students to be brave enough to have their say without being judged. Wish more units were like this."

"The unit was run in informal sessions that allowed for personal expression and growth. The unit presents a variety of experiences and allows students to individually develop without fear of judgement and without being pushy. Very skilful!"

Students commented on the transformational nature of the journey provided by the unit, which spoke to the very core of the individual student's identity, self-perception and understanding of Australia and their place within it. Quantitative feedback suggests that IAHC has raised the confidence of the majority of students to positively interact with Indigenous Australians and suggests the beginning of their journey along the continuum of Indigenous intercultural competency.

"This unit has not only helped me understand aspects of Indigenous culture but also their people. This is such a fulfilling unit that kept me interested and prepared for my interaction with Indigenous people. This unit is the first step to help 'close the gap', by involving students and teachers to help create a better understanding of issues faced by Indigenous people."

"I think the unit has a lot of potential.. i picked up concepts that i wouldn't have without this unit that will stay with me for my whole career"

"The unit has helped me gain a greater understanding of how past events have impacted on today and future generations of indigenous people in relation to their health. Also for use for nurses to recognise the importance of culturally appropriate communication when treating a indigenous person." 
"I enjoyed every aspect of this unit, I found it very helpful to be able to talk to the whole class and the tutor about very controversial issues. I learnt so much about the stolen generations. I feel that I am better prepared for indigenous clients thanks to this unit."

\section{Discussion}

Student feedback from the University's online student survey of teaching and learning indicates that the majority of students were motivated by the teaching and unit design, and were satisfied with the unit.

General lower student satisfaction in 2006, its first iteration, likely reflects teething issues in the unit design, delivery, coordination, and possibly challenges related to disciplinary cultural change. As has been discussed, compulsory Indigenous Australian content is challenging to teach when the relevance of the content is not always immediately apparent to predominately European students who are unaware of the privilege associated with their racial and cultural identity. Similarly, international students not planning to work in Australia may also initially question the value of the content until the application of the knowledge gained in IAHC is applied to other minority groups and local indigenous peoples.

In this way, intercultural education provides opportunities for students to develop not just cultural skills, but also other key graduate capabilities such as communication and reflective skills through the exploration of differing cultural perspectives and practices. For example, communication skills can be enhanced by opening students' eyes to different ways of communicating and through encouraging reflection on their own communication style and behaviour. The comments above suggest that IAHC is contributing to students developing an awareness of different cultural communication practices and the need to alter communication in different contexts with different people. Furthermore, units such as IAHC challenge students to reconsider their cultural perspective as one of many as Western authority undergoes a consistent unsettling through privileging Aboriginal and Torres Strait Islander viewpoints (Williamson \& Dalal, 2007). Students are, consequently, encouraged to develop an understanding of power and knowledge systems in racial terms thus supporting the development of critical thinking. For European Australians this can be particularly transformative as students are given the opportunity to reflect on their own cultural and racial identity which is typically normalised; it is the neutral or invisible racial and ethnic identity against which all others are measured. For example, generally when white people (and dominant discourses) speak of 'ethnic identities' they are referring to groups other than European Australian. Naming whiteness and its associated privilege can be challenging for some students as most have given little or no thought to their racial identity and associated privilege, and how their own complacency could reinforce institutional and other forms of racism (Lawrence \& Bunche, 1996). Teaching Indigenous Australian cultural competence is thus challenging and complex as it often speaks directly to individuals' own racial identity, unsettling and destabilising self-perceptions and value systems. Minority groups, on the other hand, constantly negotiate the cultural interface; to survive they must learn the dominant group's code (Fanon, 1952).

The story of one mature-aged non-Indigenous student of IAHC shows how the teaching team of IAHC impacted positively on student views. This student began the course very negatively, resenting the compulsory nature of the unit, arguing that it was simply political correctness (Grafton \& Lye, 2000). The student did not see its value or relevance to them as a professional. During the semester, however, the student's views were transformed. The student recounted an experience at a dinner party they hosted where a guest began to make a racist joke about Aboriginal people. The student reported in the tutorial- to their own surprise and their spouses'-how they had felt compelled to challenge their guest. The same student commented that the course had made them 'take a look at' themself, and that they

Flavell, H., Thackrah, R. \& Hoffman, R. (2013). Developing Indigenous cultural competence: A model for implementing Indigenous content into curricula.

Journal of Teaching and Learning for Graduate Employability, 4(1), 39-63. 
didn't want their children to be as judgemental as they had been. The student wanted to ensure they understood Australian history from an Aboriginal perspective. This story highlights that many students do not initially appreciate the importance of a compulsory unit on Indigenous Australian studies. Some students may never realise the importance of this content during a twelve-week course which is why it is important that content is scaffolded throughout a program of study. A unit such as IAHC, however, does have the potential to shift the majority of students' views if taught using an appropriate pedagogical approach that recognises the challenges and complexities of teaching in this space. Furthermore, for sustained and meaningful change to occur the principles that inform a Reconciliation Action Plan-which underpinned the design, implementation and continuation of IAHC over five years—-must be addressed. That is: relationships, respect and opportunities.

A lack of Aboriginal and Torres Strait Islander academics and students has been documented by non-Aboriginal administrators and the sector struggles with how to be more inclusive. The exploration of the IAHC unit presented here provides some potential guidelines, however, in the rush to Indigenise the curriculum and instil in all graduates Indigenous cultural competency it is important that Indigenous Australian academics are not further overburdened and a critical understanding of cultural competency be embraced. Research undertaken into Aboriginal and Torres Strait Islander academics shows there is already a large amount of unacknowledged cultural work that goes on (Page \& Asmar, 2004, 2008). This is consistent with research into minority academics in the United States (Tierney \& Bensimon, 1996). Furthermore, the emotional labour for an Aboriginal or Torres Strait Islander academic associated with teaching non-Indigenous students is considerable, as resistant and or racist non-Indigenous students are common (Asmar \& Page, 2009). The cultural knowledge and experience of Aboriginal and Torres Strait Islander academics, as well as their existing unacknowledged work, must be formally recognised and valued within the tertiary sector if the goal of graduate Indigenous cultural competency is to be achieved.

\section{Conclusion}

The qualitative comments from students of IAHC indicate that the unit has impacted on the development of Indigenous Australian cultural competence. Key to the success of the unit, however, was that it was designed and delivered in a partnership with Aboriginal and nonAboriginal academics underpinned by a Memorandum of Understanding foregrounding Aboriginal Terms of Reference. Relationship building and reciprocity were key elements in the partnership. This was achieved through recognising the centrality and importance of relationships, the local Nyungar community, and through recognising Aboriginal knowledge as a 'way of being' linked strongly to spirituality, land and community rather than content to be inserted into curriculum (Yunkaporta \& Kirby, 2011). These elements are crucial, particularly in a unit aimed at developing Indigenous cultural competency, as the recreation of colonial structures would not model appropriate cultural sensitivity or create cultural safety (Nakata, 2007b).

These issues, amongst others, must be considered in developing Indigenous cultural competency in Australia and suggest that non-Aboriginal academics and administrators require considerable staff development. The majority of academics do not have Indigenous Australian cultural skills for many of the same reasons that non-Aboriginal students do not have these skills. Consequently, they lack the understanding and confidence to teach Indigenous content or indeed the ability to create a culturally safe environment for Aboriginal and Torres Strait Islander colleagues and students. Changes are occurring, however, and if the current level of interest and engagement in inclusive curricula is any indication there is indeed hope for beginning graduates on their journey to Indigenous cultural competence. Further research is required, and this is beginning to be explored (for example, Ewen \& Paul, 2012), on the impact of courses and programs such as IAHC on graduate practice as well as

Flavell, H., Thackrah, R. \& Hoffman, R. (2013). Developing Indigenous cultural competence: A model for implementing Indigenous content into curricula.

Journal of Teaching and Learning for Graduate Employability, 4(1), 39-63. 
how existing organisational structures and cultures support or prevent graduates from becoming change agents to help create culturally safe organisations and service provision. 


\section{References}

Anning, B. (2010). Embedding an Indigenous graduate attribute into University of Western Sydney's Courses. The Australian Journal of Indigenous Education, 39 (Supplement), 4052.

Asmar, C. \& Page, S. (2009). Sources of satisfaction and stress among Indigenous academic teachers: Findings from a national Australian study. Asia Pacific Journal of Education, 29(3), 387-401. doi: 10.1080/02188790903097505

ATSIC. (1999). As a matter of fact: Answering the myths and misconceptions about Indigenous Australia. Canberra: Office of Public Affairs.

Australian Institute for Teaching and School Leadership (Ed.). (2012). Retrieved from http://www.teacherstandards.aitsl.edu.au/OrganisationStandards/Organisation . Melbourne: Australian Institute for Teaching and School Leadership.

Banks, J. (1994). Multiethnic education: Theory and practice. Needham Heights, MA: Allyn and Bacon.

Behrendt, L., Larkin, S., Griew, R. \& Kelly, P. (2012). Review of higher education access and outcomes for Aboriginal and Torres Strait Islander people. Final Report. Canberra:

Australian Government. Retrieved from

http://www.innovation.gov.au/HigherEducation/IndigenousHigherEducation/ReviewOfIndig enousHigherEducation/FinalReport/index.html

Bessarab, D. \& Ng'andu, B. (2010). Yarning about yarning as a legitimate method in Indigenous research. International Journal of Critical Indigenous Studies, 3(1), 37-50.

Campinha-Bacote, J. (2002). The process of cultural competence in the delivery of healthcare services: A model of care. Journal of Transcultural Nursing, 13(3), 181-184.

Carpenter-Song, E. A., Nordquest Schwallie, M. \& Longhofer, J. (2007). Cultural competence reexamined: Critique and directions for the future. Psychiatric Services, 58(10), 1362-1365.

Charles Sturt University. (2013). Indigenous curriculum \& pedadogy: Brief literature review of pedagogy in Indigenous cultural competence. Retrieved May 1, 2013, from http://www.csu.edu.au/division/landt/indigenous-curriculum/cultural-competence/lite-review

Coffin, J. (2007). Rising to the challenge in Aboriginal health by creating cultural security. Aboriginal \& Islander Health Worker Journal, 31(3), 22-24.

Collard, K., Walker, R. \& Dudgeon, P. (1998). Aboriginalising the curriculum: A disciplined approach? (Vol. 16). Perth: Curtin Indigenous Research Centre.

Crey, K. \& Perrault, A. H. (2007). What I learnt in the class today: Aboriginal issues in the classroom. Retrieved from www.issuesintheclass.com

de la Harpe, B., Radloff, A., Scoufis, M., Dalton, H., Thomas, J., Lawson, A., ... \& Girardi, A. (2009). The $B$ factor project: Understanding academic staff beliefs about graduate attributes. Surry Hills: Australian Learning and Teaching Council.

Downing, R. \& Kowal, E. (2011). A postcolonial analysis of Indigenous cultural awareness training for health workers. Health Sociology Review, 20(1), 5-15.

Duff, A., Brodie, T., Furber-Gillick, D., Quinn, D. \& Smith, E. (2011). Do with and not to. Building cultural understanding, enabling communication and promoting the spirit of reconciliation in first year engineering. Paper presented at the Australasian Association for Engineering Education Fremantle, Western Australia.

Duffy, M., Harju, L., Huittinen, L. \& Trayner, C. (1999). An innovative model: International undergraduate education. Nursing and Health Care Perspectives, 20, 26-31.

Eckermann, A.K., Down, T., Chong, E., Nixon, L., Fray, R. \& Johnson, S. (2010). Binan Gooniji: Bridging cultures in Aboriginal health (3rd ed.). Chatswood, NSW: Elsevier.

Flavell, H., Thackrah, R. \& Hoffman, R. (2013). Developing Indigenous cultural competence: A model for implementing Indigenous content into curricula. 
Ewen, S. C. \& Paul, D. J. (2012). Do Indigenous health curricula in health science education reduce disparities in health care outcomes? Medical Education, 197(1), 50-52.

Fanon, F. (1952). Black skin, white masks (R. Philcox, Trans.). New York: Grove Press.

Gower, G., Nakata, M. \& Mackean, T. (2007). Achieving appropriate outcomes in the teaching of Indigenous Australian studies in universities. Paper presented at the 3rd Annual IHEAC Conference, Adelaide.

Grafton, J. \& Lye, J. (2000). Political correctness, surface tension and passive racism: A preliminary analysis of students' lived experiences of cultural diversity at the University of Melbourne. Youth Studies Australia, 19(3), 44-51.

Grant, J., Parry, Y. \& Geurin, P. (2013). An investigation of cutlurally competent terminology in healthcare policy finds ambiguity and lack of definition. Australian and New Zealand Journal of Public Health, 37(3).

Grote, E. (2008). Principles and practices of cultural competency: A review of the literature. Retrieved from http://foi.deewr.gov.au/documents/principles-and-practices-culturalcompetency-review-literature

Gunstone, A. (2009). Whiteness, Indigenous peoples and Australian universities. Australian Critical Race and Whiteness Studies Association e-journal. 1. Retrieved from http://www.acrawsa.org.au/files/ejournalfiles/44acrawsa517.pdf

Health Workforce Australia. (2013). Aboriginal and Torres Strait Islander health curriculum framework. Retrieved from http://www.hwa.gov.au/work-programs/workforce-innovationand-reform/atsihw/health-curriculum-framework

Helms, J. (1990). Black and white racial identity: Theory, research and practice. New York: Greenwood.

Howard, G. R. (1999). You can't teach what you don't know: White teachers, mulit-racial schools. New York: Teachers College Press, Columbia University.

Indigenous Higher Education Advisory Council. (2006). Improving Indigenous outcomes and enhancing Indigenous culture and knowledge in Australian higher education. Report to the Minister for Education, Science and Training. Retrieved from http://foi.deewr.gov.au/documents/improving-indigenous-outcomes-and-enhancingindigenous-culture-and-knowledge-australian

Jarvis-Selinger, S., Ho, K., Novak Lauscher, H., Liman, Y., Stacy, E., Woollard, R. \& Butote, D. (2008). Social accountability in action: University-community collaboration in the development of an interprofessional Aboriginal health elective. Journal of Interprofessional Care, 22 (Supplement), 61-72S.

Kickett, M., Hoffman, J. \& Flavell, H. (2013 ). A model for large scale, interprofessional, compulsory cross-cultural education with an Indigenous focus. Journal of Allied Health, in press.

Lawrence, S. M. \& Bunche, T. (1996). Feeling and dealing: Teaching white students about racial privilege. Teaching and Teacher Education, 12(5), 531-542. doi: 10.1016/0742051x(95)00054-n

Leaders in Indigenous Medical Education (LIME). The LIME Network. Retrieved 16 May, 2013, from http://www.limenetwork.net.au/content/pedagogical-principles-approach

LIME. (2012). The LIME Good Practice Case Studies. http://www.limenetwork.net.au/content/good-practice-case-studies

MacMillan, F. (2013). Position Paper - Culturally Responsive Health Care. In I. A. H. Australia (Ed.). ACT: Indigenous Allied Health Australia.

McAllister, G. \& Irvine, J. (2000). Cross cultural competency and multicultural teacher education. Review of Educational Research, 7(3), 3-24. 
Mickler, S. (1998). The myth of privilege: Aboriginal status, media visions, public ideas. Fremantle, Western Australia: Fremantle Arts Centre Press.

Mitchell, M., Every, D. \& Ranzijn, R. (2011). Everyday antiracism in interpersonal contexts: Constraining and facilitating factors for 'speaking up' against racisim. Journal of Community and Applied Psychology, 21, 329-341. doi: 10.1002/casp.1077

Morgan, S. \& Golding, B. (2010). Crossing over: Collaborative and cross-cultural teaching of Indigenous education in a higher education context. The Australian Journal of Indigenous Education, 39 (Supplement), 8-14.

Nakata, M. (2007a). The cultural interface. The Australian Journal of Indigenous Education, 36 (Supplement), 7-14.

Nakata, M. (2007b). Disciplining the Savages: Savaging the disciplines. Canberra: Aboriginal Studies Press.

Nakata, M., Nakata, K. \& Chin, M. (2008). Approaches to the academic preparation and support of Australian Indigenous students for tertiary studies. The Australian Journal of Indigenous Education, 37 (Supplement), 137-145

Nash, R., Mieklejohn, B. \& Sacre, S. (2006). The Yapunyah project: Embedding Aboriginal and Torres Strait Islander perspectives in the nursing curriculum. Contemporary Nurse, 22(2), 296-316.

O'Dowd, M. (2010). 'Ethical positioning' a strategy in overcoming student resistance and fostering engagement in teaching Aboriginal history as a compulsory subject to preservice primary education students. Education in Rural Australia, 20(1), 29-42.

Office of Aboriginal and Torres Strait Islander Health. (2002). gettin em $n$ keeping ems. Report of the Indigenous Nursing Education Working Group to the Commonwealth Department of Health and Ageing. Office of Aboriginal and Torres Strait Islander Health.

Oliver, B. (2011). Good Practice Report: Assuring Graduate Outcomes. NSW: Australian Learning and Teaching Council.

Page, S. \& Asmar, C. (2004). Indigenous academic voices: Stories from the tertiary education frontline. HERDSA News, 26(1), 13-15.

Page, S. \& Asmar, C. (2008). Beneath the teaching iceberg: Exposing the hidden support dimensions of Indigenous academic work. Australian Journal of Indigenous Education, 37(2008), 109-117.

Phillips, G. (2004). CDAMS Indigenous Health Curriculum Framework. Melbourne: Committee of Deans of Australian Medical Schools.

Ranzijn, R., McConnochie, K., Nolan, W. \& Day, A. (2007). Teaching cultural competence in relation to Indigenous Australians: Steps along a journey. InPsych: The Bulletin of the Australian Psychological Society Limited, 32(4), 10-11.

Ranzijn, R., Nolan, W., McConnochie, K., Hodgson, L., Spurrier, W. \& Passmore, G. (2008). Disseminating strategies for incorporating Australian Indigenous content into psychology undergraduate programs throughout Australia. Final Report. NSW: Australian Learning and Teaching Council. Retrieved from http://www.olt.gov.au/resources?text=ranzijn

Raymond, L. M. (2008). Developing a new Bachelor of Nursing course responsive to Australia's culturally diverse community. Contemporary Nurse, 28, 17-22.

Singleton, G. \& Linton, C. (2006). Courageous conversations about race. Thousand Oaks, California: Corwin Press Inc.

Tervalon, M. \& Murray-Garcia, J. (1998). Cultural humility versus cultural competence: A critical distinction in defining physician training outcomes in multicultural education. Journal of Healthcare for the Poor and Underserved, 9(2), 117-125.

Thackrah, R. \& Thompson, S. (2013). Refining the concept of cultural competence: Building decades of progress. Medical Journal of Australia, 199(1), 35-38.

Flavell, H., Thackrah, R. \& Hoffman, R. (2013). Developing Indigenous cultural competence: A model for implementing 
Tierney, W. G. \& Bensimon, E. M. (1996). Promotion and tenure: Community and socialization in the academe. Albany, NY: State University of New York Press.

Tucker, B. \& Pegden, J. (2010). Closing the loop: A holistic approach to student feedback at Curtin. Paper presented at the Australasian Higher Education Evaluation Forum (AHEEF), Lincoln University, Christchurch, New Zealand.

Turale, S. \& Miller, M. (2006). Improving the health of Indigenous Australians: Reforms in nursing education. An opinion piece of international interest. International Nursing Review, 53(3), 171-177.

Universities Australia. (2011). Guiding principles for developing Indigenous competency in Australian universities. Canberra, ACT: Department of Education, Employment and Workplace Relations (DEEWR).

White, N., Frawley, J. \& Dang Thi, K. A. (2013). Good Practice Report: Innovative Indigenous Teaching and Learning. NSW: Office for Learning and Teaching. Retrieved from http://www.olt.gov.au/resources?text=white\%2C+nereda

Williams, R. (2000). 'Why should I feel guilty?' Reflections on the workings of guilt in white Aboriginal relations. Australian Psychologist, 35(2), 136-142.

Williamson, J. \& Dalal, P. (2007). Indigenising the curriculum or negotiating the tensions at the cultural interface? Embedding Indigenous perspectives and pedagogies in a university curriculum. The Australian Journal of Indigenous Education, 36 (Supplement), 51-58.

Wimshurst, K., Marchetti, E. \& Allard, T. (2004). The attitudes of criminal justice students to Australian Indigenous people: Does higher education influence student perceptions? Journal of Criminal Justice Education, 15(2), 327-350.

Yorke, M. (2006). Employability in higher education: What it is - what it is not. Learning and Employability Series (1). York: Higher Education Academy.

Yunkaporta, T. \& Kirby, M. (2011). Yarning up Indigenous pedagogies: A dialogue about eight Aboriginal ways of learning. In R. Bell, G. Milgate \& N. Purdie (Eds.). Two way teaching and learning: Toward culturally reflective and relevant education Victoria: ACER Press, (pp. 205-213). 